\title{
Development of an MRI-visible nonviral vector for siRNA delivery targeting gastric cancer
}

This article was published in the following Dove Press journal:

International Journal of Nanomedicine

31 January 2012

Number of times this article has been viewed

\author{
Yinting Chen' \\ Weiwei Wang ${ }^{2}$ \\ Guoda Lian' \\ Chenchen Qian' \\ Lingyun Wang' \\ Linjuan Zeng' \\ Chengde Liao $^{3}$ \\ Biling Liang ${ }^{4}$ \\ Bing Huang 5 \\ Kaihong Huang' \\ Xintao Shuai ${ }^{2}$ \\ 'Department of Gastroenterology, \\ The Second Affiliated Hospital of \\ Sun Yat-sen University, Guangzhou, \\ ${ }^{2}$ Center of Biomedical Engineering, \\ School of Chemistry and Chemical \\ Engineering, Sun Yat-sen University, \\ Guangzhou, ${ }^{3}$ Department of \\ Radiology, The Third Affiliated \\ Hospital of Kunming Medical \\ University, Kunming, ${ }^{4}$ Department \\ of Radiology, The Second Affiliated \\ Hospital of Sun Yat-sen University, \\ Guangzhou, ${ }^{5}$ Center of Animal \\ Research, Zhongshan Ophthalmic \\ Center Hospital of Sun Yat-sen \\ University, Guangzhou, China
}

Correspondence: Kaihong Huang

Department of Gastroenterology,

The Second Affiliated Hospital of

Sun Yat-sen University,

Guangzhou, China

Tel +862081332489

Fax +86 2081332244

Email kaihonghuang@yahoo.cn

Xintao Shuai

Center of Biomedical Engineering,

School of Chemistry and Chemical

Engineering, Sun Yat-sen University,

Guangzhou, China

Tel +86 2084II 2105

Fax +86 20 84II 2245

Email shuaixt@mail.sysu.edu.cn
Abstract: An antibody-directed nonviral vector, polyethylene glycol-grafted polyethylenimine functionalized with superparamagnetic iron oxide nanoparticles and a gastric cancer-associated CD44v6 single-chain variable fragment ( $\left.\mathrm{scFv}_{\mathrm{CD} 44 \mathrm{v} 6},-\mathrm{PEG}-\mathrm{g}-\mathrm{PEI}-\mathrm{SPION}\right)$, was constructed as a gastric cancer-targeting and magnetic resonance imaging (MRI)-visible nanocarrier for small interfering RNA (siRNA) delivery. Biophysical characterization of PEG-g-PEI-SPION and $\mathrm{ScFv}_{\mathrm{CD} 44 \mathrm{v} 6}$-PEG-g-PEI-SPION was carried out, including siRNA condensation capacity, cell viability, and transfection efficiency. Both the targeting and nontargeting nanocarriers were effective for transferring siRNA in vitro. The cellular uptake and distribution of nanoparticles complexed with siRNA was analyzed by fluorescence imaging and immunofluorescent staining. Moreover, the gastric cancer-targeting effect was verified in vivo by MRI and histology analysis. These results indicate that $\mathrm{scFv}_{\mathrm{CD} 44 \mathrm{v} 6}$-PEG-g-PEI-SPION is a promising nonviral vector for gastric cancer gene therapy and diagnosis.

Keywords: tumor targeting, CD44 variant 6, nonviral vector, small interfering RNA, magnetic resonance imaging

\section{Introduction}

Gastric cancer is one of the most frequently diagnosed and aggressive carcinomas of the gastrointestinal tract, especially in East Asian countries, including China, Japan, and Korea. ${ }^{1-4}$ Although gastric cancer is considered chemosensitive, the prognosis is still poor because of lymph node metastasis, hematogenous metastasis, and peritoneal dissemination. ${ }^{3}$ Small interfering RNA (siRNA) therapy is a promising therapeutic method but is severely hampered due to its lack of an ideal delivery system. One promising approach to overcoming this limitation is the application of targeted-release systems that are recognized by a specific cell receptor mediating endocytosis. Until now, the development of safe, efficient, and targetable siRNA delivery systems remains a big challenge in cancer therapy. To develop such a targeted delivery agent, potent siRNA transport vehicles and smallmolecule targeting at specific cancer cells are two essential elements. So far, siRNA delivery vehicles can be categorized into two main groups, ie, viral and nonviral systems. ${ }^{5}$ The viral vector has high efficiency in siRNA transfer, but its cytotoxicity and limitation in terms of the size of the inserted genetic materials should be considered. ${ }^{6}$ In comparison, nonviral carriers, such as cationic polymers, cationic peptides, and cationic lipids (liposomes) can overcome these shortcomings. Among the various nonviral carriers, polyethyleneimine, which contains primary, secondary, and tertiary amines to complex with nucleic acids such as DNA and 
siRNA, is one of the most widely studied cationic polymers for gene and siRNA therapies. In addition, polyethyleneimine can be easily modified by attaching small molecules to enable specific targeting ability. However, polyethyleneimine-based siRNA delivery may induce cell cytotoxicity, depending on the molecular weight and concentration of the polymer, due to electrostatic interactions between polyethyleneimine and the negatively charged components of the cell membrane, such as sialic acid. Therefore, polyethylene glycol (PEG) with neutral hydrophilic polymers is attached to polyethyleneimine (PEG-g-PEI) to reduce cytotoxicity while maintaining considerable siRNA transfer efficiency. ${ }^{7-11}$ In our previous study, PEG-g-PEI was shown to be a desirable nanoparticle carrier with relatively high siRNA delivery efficiency and low cytotoxicity. ${ }^{12}$ Meanwhile, magnetic resonance imaging (MRI) techniques have great advantages in monitoring targeting events and therapeutic outcomes noninvasively. MRI-visible nanoparticulate systems have been used for anticancer drug delivery and molecular imaging of cancer. ${ }^{13,14}$ To construct a nanoparticulate carrier combining siRNA delivery and MRI function, superparamagnetic iron oxide nanoparticles (SPION), known to be a highly efficient $\mathrm{T}_{2}$ contrast agent for MRI, was attached to PEG-g-PEI (PEGg-PEI-SPION), making the vector MRI-visible. ${ }^{15}$

Antibodies have great potential to be applied as targeting ligands for antibody-mediated diagnostic and therapeutic agents because of their high specificity and affinity for target antigens. However, clinical application of antibodies has been limited because of their large molecular size (150 kDa) and the harmful immune response in patients. Single-chain variable fragment $(\mathrm{scFv})$, which contains variable domains of the heavy chain $\left(\mathrm{V}_{\mathrm{H}}\right)$ and the light chain $\left(\mathrm{V}_{\mathrm{L}}\right)$, connected by a flexible peptide linker, has the smallest antibody fragment $(25 \mathrm{kDa})$ that retains specific binding characteristics without attacking the immune system. Cancer-targeting antibodies should be targeted against the appropriate antigen with high expression in tumor tissues but almost no expression in normal tissues. So far, various cell surface markers and/or receptors, including those associated with cancer, have been explored as potential targets. CD44 variant 6 (CD44v6) is an ideal target antigen that displays a favorable pattern of expression according to present studies. CD44v6 is a cancerassociated antigen that is mainly expressed in a subset of adenocarcinomas, and has been identified as a protein marker for metastatic behavior in epithelium-derived cancers, such as hepatocellular, breast, colorectal, and gastric cancers. ${ }^{16-19}$ In a previous study, we generated a stable antihuman $\mathrm{CD} 44 \mathrm{v} 6 \mathrm{scFv}\left(\mathrm{scFv}_{\mathrm{CD} 44 \mathrm{v} 6}\right)$ and analyzed its cancer-targeting ability in vitro. ${ }^{20}$ It could be attached to a nanoparticle vector for transporting foreign materials effectively to the targeted tissues for cancer diagnosis and therapeutics.

In this report, an antibody-directed nanoparticulate vector was generated by attaching $\mathrm{ScFv}_{\mathrm{CD} 44 \mathrm{v} 6}$ to PEG-g-PEI-SPION ( $\mathrm{scFv}_{\mathrm{CD} 44 \mathrm{v} 6}$-PEG-g-PEI-SPION). Both PEG-g-PEI-SPION and $\mathrm{scFV}_{\mathrm{CD} 44 \mathrm{v} 6}-\mathrm{PEG}-\mathrm{g}$-PEI-SPION were investigated in terms of siRNA complexation capacity and transfection efficiency. Cellular uptake and distribution of nanoparticles complexed with siRNA was demonstrated by fluorescence imaging and immunofluorescent staining experiments. Finally, the in vivo gastric cancer-targeting effect of $\mathrm{scFv}_{\mathrm{CD} 44 \mathrm{v} 6}$-PEG-g-PEI-SPION was determined by MRI and histological analysis.

\section{Materials and methods}

\section{Synthesis of $\mathrm{scFv}_{\mathrm{CD} 44 v 6}$-PEG-g-PEI-SPION}

Hydrophobic SPION measuring $6 \mathrm{~nm}$ average diameter was synthesized following the method reported by Sun et al. ${ }^{21}$ The structure of the particles was characterized using selected area electron diffraction. The measured particle lattice spacing matched very closely to the published Joint Committee on Powder Diffraction Standards International Center for Diffraction Data for magnetite in 2000, indicating that the particle composition is $\mathrm{Fe}_{3} \mathrm{O}_{4} \cdot{ }^{22}$

The targeting vector complexed with SPION, ie, $\mathrm{scFv}_{\mathrm{CD}_{44} \mathrm{v}^{-}}$ PEG-g-PEI-SPION, was prepared based on PEG $2 \mathrm{kDa}$ and polyethyleneimine $25 \mathrm{kDa}$ at a PEG/PEI molar ratio of 10:1 as reported previously. ${ }^{15}$ Antihuman CD44v6 single-chain variable fragment $\left(\mathrm{scFv}_{\mathrm{CD} 44 \mathrm{v} 6}\right)$ was generated as described in our previous study. ${ }^{20}$ The heterofunctional PEG terminated by carboxyl and maleimide groups (MAL-PEG-COOH) with a molecular weight of $3.7 \mathrm{kDa}$ was synthesized in our laboratory as described elsewhere. ${ }^{15}$ To synthesize the antibody-targeted delivery vector, $10 \mu \mathrm{g}$ of $\mathrm{scFv}_{\mathrm{CD} 44 \mathrm{v} 6}$ was dissolved in a mixture of $40 \mu \mathrm{L}$ phosphate-buffered solution (pH 7.4) and $10 \mu \mathrm{L}$ ethylenediamine tetra-acetic acid aqueous solution. A $10 \mu \mathrm{g}$ sample of MAL-PEG-COOH was dissolved in $10 \mu \mathrm{L}$ of phosphate-buffered solution containing $10 \mu \mathrm{L}$ of $0.5 \mathrm{M}$ ethylenediamine tetra-acetic acid solution and then added into the antibody solution. Afterwards, the solution was incubated overnight at $4^{\circ} \mathrm{C}$. The resulting solution containing $\mathrm{scFv}_{\mathrm{CD} 44 \mathrm{v} 6}$-functionalized PEG ( $\mathrm{scFv}_{\mathrm{CD} 44 \mathrm{v} 6}$-PEG-COOH) was washed three times with phosphate-buffered solution using ultrafiltration (Amicon, molecular weight cutoff $5 \mathrm{kDa}$ ). Dicyclohexylcarbodiimide $5 \mu \mathrm{g}$, N-hydroxysuccinimide $5 \mu \mathrm{g}$, and PEG-g-PEI-SPION $50 \mu \mathrm{g}$ were added into the purified solution. The solution was adjusted to $200 \mu \mathrm{L}$ with phosphate-buffered solution and incubated overnight 
at $4{ }^{\circ} \mathrm{C}$ to form $\mathrm{scFv}_{\mathrm{CD}_{446} 6}-\mathrm{PEG}$-g-PEI-SPION. The content of SPION in PEG-g-PEI-SPION was 55\%, and the content of $\mathrm{scFv}_{\mathrm{CD} 44 \mathrm{v} 6}$ in $\mathrm{scFv}_{\mathrm{CD} 44 \mathrm{v} 6}-\mathrm{PEG}$-g-PEI-SPION was $16.7 \%$. Because $\mathrm{scFv}_{\mathrm{CD} 44 \mathrm{v} 6}$ itself contains sulfhydryl groups rather than disulfide bonds, the above synthetic approach was even easier than the method reported for preparing the CD3 functionalized antibody vectors. ${ }^{15}$

\section{Agarose gel electrophoresis and hydrodynamic diameter measurement}

The binding ability of siRNA with PEG-g-PEI-SPION and $\mathrm{ScFv}_{\mathrm{CD} 44 \mathrm{v} 6}$-PEG-g-PEI-SPION was determined by agarose gel electrophoresis. Complexes of PEG-g-PEI-SPION/ siRNA and $\mathrm{scFv}_{\mathrm{CD} 44 \mathrm{v} 6}$-PEG-g-PEI-SPION/siRNA were formed by mixing human negative control siRNA (siNC, Guangzhou RiboBio Ltd, Guangzhou, China) and PEG-gPEI-SPION or $\mathrm{scFv}_{\mathrm{CD} 44 \mathrm{v} 6}-\mathrm{PEG}$-g-PEI-SPION at N/P ratios of $2.5,5,10,15$, and 20 in $500 \mu \mathrm{L}$ deionized water. N/P ratios were calculated as the ratio of nitrogen $(\mathrm{N})$ in the polymer over phosphate $(\mathrm{P})$ in nucleic acid. The amount of siRNA for each sample was 10 pmol. Complexes were then incubated for 10-15 minutes at room temperature to allow polyplex formation. Subsequently, complexes were mixed with $6 \times$ agarose gel loading dye mixture and $10 \times$ colloidal gold. The mixture was loaded onto $1 \%(\mathrm{w} / \mathrm{v})$ agarose gel and ran with $0.5 \times$ Tris-borate-ethylenediamine tetra-acetic acid running buffer at $100 \mathrm{~V}$ for 20 minutes. The siRNA bands were visualized by an ultraviolet imaging system (Uvidoc, UVItec Ltd, Cambridge, UK).

Moreover, the hydrodynamic diameter values of $\mathrm{scFv}_{\mathrm{CD} 44 \mathrm{v} 6}-\mathrm{PEG}-\mathrm{g}-\mathrm{PEI}-\mathrm{SPION}$ and $\mathrm{scFv}_{\mathrm{CD} 44 \mathrm{v} 6}$-PEG-g-PEISPION/siRNA were determined by dynamic light scattering measurements. $\mathrm{scFv}_{\mathrm{CD} 44 \mathrm{v} 6}$-PEG-g-PEI-SPION/siRNA was prepared as described above at N/P ratios of 5, 10, 15, and 20 . Subsequently, $\mathrm{scF}_{\mathrm{CD} 44 \mathrm{v} 6}-\mathrm{PEG}-\mathrm{g}-\mathrm{PEI}-\mathrm{SPION}$ and $\mathrm{scF}_{\mathrm{CD} 44 \mathrm{v} 6}$ PEG-g-PEI-SPION/siRNA were measured for hydrodynamic sizes using a ZetaPlus instrument (Brookhaven, NY). The position and attenuator were optimized by the device. Measurements were conducted for five runs.

\section{Cell viability assay}

A 3-(4,5-dimethylthiazol-2-yl)-2,5-diphenyl tetrazolium bromide (MTT) assay was performed to evaluate the influence of the PEG-g-PEI-SPION/siRNA and $\mathrm{scFv}_{\mathrm{CD} 44 \mathrm{v} 6}{ }^{-}$ PEG-g-PEI-SPION/siRNA complexes on cell viability. A human gastric carcinoma cell line SGC-7901 was obtained from the Institute of Biochemistry and Cell Biology, Chinese Academy of Sciences (Shanghai, China). Cells were cultured and maintained in Dulbecco's modified Eagle's medium (HyClone, Thermo Scientific, Logan, UT) supplemented with 10\% fetal bovine serum (HyClone), 4 mM L-glutamine, $100 \mathrm{U} / \mathrm{mL}$ penicillin, and $100 \mu \mathrm{g} / \mathrm{mL}$ streptomycin in a humid atmosphere of $5 \% \mathrm{CO}_{2} / 95 \%$ air at $37^{\circ} \mathrm{C}$. SGC-7901 cells were seeded at a density of $5 \times 10^{3}$ cells per well in a 96-well plate and cultured for 24 hours at $37^{\circ} \mathrm{C}$. Polyplexes of PEGg-PEI-SPION/siRNA and $\mathrm{scFv}_{\mathrm{CD} 44 \mathrm{v} 6}$-PEG-g-PEI-SPION/ siRNA were prepared as described above at various N/P ratios of $2.5,5,10,15$ and 20 , together with cell culture medium $(200 \mu \mathrm{L})$ were added to each well, and the siRNA concentration in each well was set to $100 \mathrm{nM}$. After cell incubation for 48 hours in the presence of polyplexes, $20 \mu \mathrm{L}$ of MTT solution (Sigma, St Louis, MO) at $5 \mathrm{mg} / \mathrm{mL}$ in saline solution was added to each well. After incubation for four hours, the medium was removed and formazan crystals were solubilized with dimethyl sulfoxide for 10 minutes at room temperature. The absorbance at $492 \mathrm{~nm}$ was determined for each well using an enzyme-linked immunosorbent assay reader (Labsystem Dragon, Oy, Finland). Cell viability was determined by the following equation:

$$
\text { Cell viability }(\%)=\left(\mathrm{A}_{\text {test }} / \mathrm{A}_{\text {control }}\right) \times 100 \%
$$

where $\mathrm{A}_{\text {test }}$ was the absorbance of the test sample and $\mathrm{A}_{\text {control }}$ was the absorbance of control sample. Experiments were performed in triplicate wells, and results were given as the mean of three independent measurements.

\section{Cell transfection and flow cytometry analyses}

The Cy3-labeled human negative control siRNA (siNC-Cy3, Guangzhou RiboBio Ltd) was used to evaluate transfection efficiency of PEG-g-PEI-SPION and $\mathrm{scFv}_{\mathrm{CD} 44 \mathrm{v} 6}$-PEG-g-PEISPION in SGC-7901 cells with Lipofectamine ${ }^{\mathrm{TM}}$ used as the control by flow cytometry. SGC-7901 cells were seeded in a six-well plate at an initial density of $2 \times 10^{5}$ cells per well 24 hours prior to siRNA delivery. Polyplexes of PEG-g-PEISPION/siRNA and $\mathrm{scFv}_{\mathrm{CD} 44 \mathrm{v} 6}$-PEG-g-PEI-SPION/siRNA were prepared at various $\mathrm{N} / \mathrm{P}$ ratios of $5,10,15$, and 20 in $400 \mu \mathrm{L}$ phosphate-buffered solution ( $\mathrm{pH}$ 7.4) following the process mentioned above. The amount of siNC-Cy3 for each sample was 100 pmol. Moreover, Lipofectamine 2000 (Invitrogen, Carlsbad, CA) was used as the control siRNA delivery agent. The complexes or lipoplexes were then added dropwise to each well containing $1.6 \mathrm{~mL}$ fresh complete medium under shaking conditions. After incubation at $37^{\circ} \mathrm{C}$ in a $\mathrm{CO}_{2}$ incubator for four hours, the transfection medium 
was exchanged for complete medium. The cells were incubated for a further 12 hours and removed. All processes were done in the dark.

The cells were then washed and suspended in phosphatebuffered solution, detected, and analyzed using a FACSCalibur system (Becton Dickinson, Franklin Lakes, NJ). The percentage of cells that had internalized complexes or lipoplexes was determined by the number of $\mathrm{Cy} 3$ red-positive cells and expressed as transfection efficiency (\%), and the mean fluorescence intensity of those cells that had taken up polyplexes or lipoplexes served as an indirect measure of the number of internalized polyplexes. ${ }^{23}$ The cell population corresponded to gated cells, and cellular debris was not counted. All values were normalized separately to cells that received PEG-g-PEI-SPION, $\mathrm{scF}_{\mathrm{CD} 44 \mathrm{v} 6}$-PEG-g-PEI-SPION, or Lipofectamine 2000 without siNC-Cy3.

\section{Fluorescence imaging and immunofluorescent staining experiments}

To assess cellular internalization and intracellular distribution of polyplexes further, siNC-Cy3 was used in the polyplex formation. Following siRNA transfection mediated by PEG-g-PEI-SPION and $\mathrm{scFv}_{\mathrm{CD} 44 \mathrm{v} 6}$-PEG-g-PEI-SPION, fluorescence images were taken using a fluorescence microscope (Nikon, Tokyo, Japan) after washing the cells with phosphate-buffered solution ( $\mathrm{pH} 7.4)$. The cells were then fixed with $4 \%$ formaldehyde/phosphate-buffered solution for 10 minutes at room temperature and washed twice with phosphate-buffered solution. The immunofluorescent staining was carried out based on $6 \times$ His tag labeled to $\mathrm{scFv}_{\mathrm{CD} 44 \mathrm{v} 6}{ }^{20}$ After nonspecific sites were blocked, fluorescein isothiocyanate-conjugated mouse monoclonal antibody against $6 \times$ His tag (Abcam, Boston MA, $10 \mu \mathrm{g} / \mathrm{mL}$ ) for $\mathrm{scFv}_{\mathrm{CD} 44 \mathrm{v} 6}$ was added to cells and incubated for 30 minutes at room temperature. Cells were then washed repeatedly, and nuclei were stained with Hoechst 33342. Photographs were taken under fluorescence microscope.

\section{Evaluation of in vivo tumor targeting by MRI}

Animal studies were performed to evaluate the tumor-targeting ability of $\mathrm{scFv}_{\mathrm{CD} 44 \mathrm{v} 6}$-PEG-g-PEI-SPION, and compared with that of PEG-g-PEI-SPION. All studies involving animals were approved by the animal care and use committee at the Institute of Biochemistry and Cell Biology, Chinese Academy of Sciences. Nude female mice (Sun Yat-sen University Animal Center, Guangzhou, China), weighing 14-16 g and aged four weeks, were handled in accordance with government guidelines. Because CD44v6 was highly expressed on SGC7901 cells, while there was hardly any expression of CD44v6 on A375 cells (human malignant melanoma cells), ${ }^{20}$ SGC7901 was selected as the target site, and A375 as the nontarget site. To induce solid tumors, $2.0 \times 10^{6} \mathrm{SGC}-7901$ cells and $3.0 \times 10^{6} \mathrm{~A} 375$ cells were subcutaneously injected bilaterally into the thigh in the same area (SGC-7901 right thigh; A375 left thigh) in 12 mice. About 7-10 days after implantation, each mouse developed bilateral thigh tumors of $200-400 \mathrm{~mm}^{3}$ in size. Twelve mice bearing SGC-7901 and A375 tumors were randomly divided into two groups.

In our previous study, SPION had been demonstrated to be a highly efficient $T_{2}$ contrast agent for MRI scaning. PEG-g-PEI-SPION could lead to hypointense $T_{2}$ signals in the liver at iron concentrations of $1.12-4.48 \mu \mathrm{g} / \mathrm{g}$ body weight in mice. As the iron concentration increased, the liver showed enhanced negative contrast in the $\mathrm{T}_{2}$-weighted images. At the injection dose of $4.48 \mu \mathrm{g} \mathrm{Fe} / \mathrm{g}$ body weight, the images showed the most obvious contrast, whether in the short-term or long-term phase. Therefore, an injection dose of $4.48 \mu \mathrm{g}$ $\mathrm{Fe} / \mathrm{g}$ body weight was chosen to detect tumors by MRI. Group $1(\mathrm{n}=6)$ was injected with $\mathrm{scFv}_{\mathrm{CD} 44 \mathrm{v} 6}$-PEG-g-PEISPION and Group $2(n=6)$ received PEG-g-PEI-SPION. The mice were anesthetized by intraperitoneal injection of $10 \%$ chloral hydrate. $\mathrm{scFv}_{\mathrm{CD} 44 \mathrm{v} 6}$-PEG-g-PEI-SPION and PEG-gPEI-SPION were injected intravenously through the tail vein at a dose of $4.48 \mu \mathrm{g} \mathrm{Fe} / \mathrm{g}$ body weight. MRI images were taken prior to injection of both SPION and at appropriate time points following injection. MRI was performed using a $1.5 \mathrm{~T}$ imaging system (Philips Medical System, Eindhoven, The Netherlands) with a $5 \mathrm{~cm}$ linearly polarized birdcage radiofrequency mouse coil (Chenguang Medical Technologies Co, Shanghai, China). $\mathrm{T}_{2}$-weighted images were acquired using a two-dimensional turbo spin echo sequence (repetition time $1600 \mathrm{msec}$, echo time $80 \mathrm{msec}$, field of view $6 \mathrm{~cm} \times 6 \mathrm{~cm}$, slice thickness $1.0 \mathrm{~mm}$, and flip angle $90^{\circ}$ ).

\section{Histology analysis}

The mice were sacrificed after the MRI studies. Tumor tissues were excised and fixed in $4 \%$ buffered paraformaldehyde for more than 48 hours and then embedded in paraffin. Adjacent slides were prepared for histological analysis using hematoxylin and eosin staining and Prussian blue staining.

\section{Statistical analysis}

All data were analyzed using SPSS version 18.0 (SPSS Inc, Chicago, IL). The results were expressed as the mean \pm standard 
error of the mean. $P<0.05$ was considered to be statistically significant. All statistical tests were two-sided.

\section{Results}

\section{Gel retardation and hydrodynamic size assay}

Agarose gel electrophoresis was conducted to confirm formation of the complex between siRNA and PEG-g-PEI-SPION or $\mathrm{scFv}_{\mathrm{CD} 44 \mathrm{v} 6}-\mathrm{PEG}-\mathrm{g}-\mathrm{PEI}-\mathrm{SPION}$. The negatively charged siRNA had mobility in the electric field. However, when PEG-g-PEI-SPION-encapsulated or $\mathrm{scFv}_{\mathrm{CD} 44 \mathrm{v} 6}$-PEG-g-PEISPION-encapsulated siRNA and complexes were formed, the high positive charge of PEG-g-PEI would neutralize the negative charge of siRNA. Moreover, depending on the N/P ratios, siRNA would partially or completely lose the negative charge, and consequently the mobility in the electric field was retarded. As shown in Figure 1, both PEGg-PEI-SPION/siRNA (Figure 1A) and $\mathrm{scFv}_{\mathrm{CD} 44 \mathrm{v} 6}-\mathrm{PEG}-\mathrm{g}-$ PEI-SPION/siRNA (Figure 1B) started to form complexes from an N/P ratio of 5, because this lane was weaker than the naked siRNA lane. In addition, at an N/P ratio from 10 to 20, the siRNA band disappeared, which indicated full complexation of siRNA chains. The hydrodynamic diameter value for $\mathrm{scFv}_{\mathrm{CD} 44 \mathrm{v} 6}-\mathrm{PEG}$-g-PEI-SPION was $79.8 \pm 2.3 \mathrm{~nm}$, and the hydrodynamic diameter values of $\mathrm{scFv}_{\mathrm{CD} 44 \mathrm{v} 6}-\mathrm{PEG}-$ g-PEI-SPION/siRNA at N/P ratios of 5, 10, 15, and 20 were $134.5 \pm 2.8 \mathrm{~nm}, 129.7 \pm 2.2 \mathrm{~nm}, 128.1 \pm 1.8 \mathrm{~nm}$, and $124.4 \pm 2.6 \mathrm{~nm}$, respectively.

\section{Cell viability analysis}

The influence of PEG-g-PEI-SPION/siRNA and $\mathrm{scF}_{\mathrm{CD}_{44 \mathrm{v} 6}}$ PEG-g-PEI-SPION/siRNA on cell viability was monitored using an MTT assay, and a human gastric carcinoma cell line (SGC-7901) was chosen as the target cell because of its high CD44v6 expression..$^{20}$ Relative cell viability was determined against cells not receiving polyplex solutions. Viability of
SGC-7901 cells exposed to PEG-g-PEI-SPION/siRNA and $\mathrm{scFv}_{\mathrm{CD} 44 \mathrm{v} 6}-\mathrm{PEG}-\mathrm{g}-\mathrm{PEI}-\mathrm{SPION} / \mathrm{siRNA}$ for 48 hours at $\mathrm{N} / \mathrm{P}$ ratios of $2.5,5,10,15$, and 20 is shown in Figure 2. Cell viability of the polyplexes decreased gradually along with increasing the N/P ratio. At an N/P ratio of 10 , the cell viability of both PEG-g-PEI-SPION/siRNA and scFv ${ }_{\mathrm{CD} 44 \mathrm{v} 6}{ }^{-}$ PEG-g-PEI-SPION/siRNA was $77.61 \% \pm 1.24 \%$ and $75.00 \% \pm 1.61 \%$, respectively. At an even higher N/P ratio of 20 , the cell viability of both groups did not decrease significantly, retaining $68.01 \% \pm 2.93 \%$ and $66.32 \% \pm 3.08 \%$ of viability, respectively. There was no statistically significant difference between these two groups at individual N/P ratios $(P<0.05)$, demonstrating that the coupling of $\mathrm{scFv}_{\mathrm{CD} 44 \mathrm{v} 6} \mathrm{did}$ not increase the cytotoxicity of PEG-g-PEI-SPION.

\section{Transfection efficiency in vitro}

The siRNA transfection efficiency of PEG-g-PEI-SPION and $\mathrm{scFv}_{\mathrm{CD} 44 \mathrm{v} 6}-\mathrm{PEG}$-g-PEI-SPION was evaluated in SGC7901 cells by flow cytometry, using Lipofectamine as the control siRNA delivery agent. As shown in Figure 3A, the transfection efficiencies of all three siRNA delivery agents at all N/P ratios ranging from 5 to 20 were over 95\%. Further, there was no statistically significant difference between them. As the N/P ratio increased, transfection efficiency did not appear higher in either PEG-g-PEI-SPION or scFv ${ }_{\mathrm{CD} 44 \mathrm{v} 6}{ }^{-}$ PEG-g-PEI-SPION. Furthermore, at the individual N/P ratios of 5, 10, 15, and 20, no statistically significant difference was shown between PEG-g-PEI-SPION and $\mathrm{scFv}_{\mathrm{CD} 44 \mathrm{v} 6}-\mathrm{PEG}-\mathrm{g}-$ PEI-SPION.

Transfection efficiency detected by flow cytometry was based on the percentage of cells that had internalized Cy3siRNA complexes. To evaluate the amount of complexes taken up by cells, mean fluorescence intensity needed to be analyzed. The mean fluorescence intensity of Lipofectamine was $133.23 \pm 4.69$, which was obviously higher than in the PEG-g-PEI-SPION and $\mathrm{scFv}_{\mathrm{CD} 44 \mathrm{v} 6}$-PEG-g-PEI-SPION groups

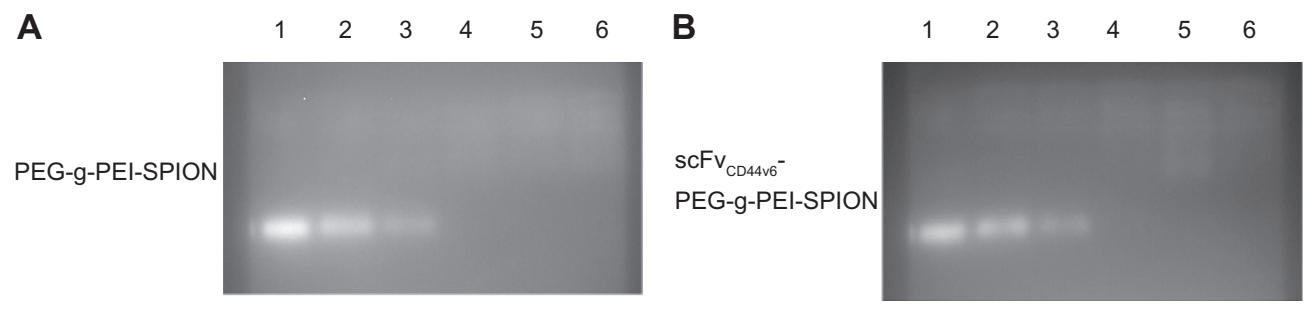

Figure I Gel retardation assay of PEG-g-PEI-SPION/siRNA and scFv ${ }_{\mathrm{CD} 44 v 6}-\mathrm{PEG}$-g-PEI-SPION/siRNA polyplexes at various N/P ratios from 2.5 to 20 . siRNA bands dissociated from polyplexes were separated by electrophoresis and visualized by an ultraviolet imaging system. Complete siRNA condensation was formed at N/P ratios of I0 and higher. Lane I, naked siRNA as a control; lanes 2-6, polyplexes formed at N/P ratios of 2.5, 5, 10, 15, and 20.

Abbreviations: PEG, polyethylene glycol; PEI, polyethyleneimine; SPION, superparamagnetic iron oxide nanoparticles; scFv ${ }_{\mathrm{CD} 44 v 6}$, cancer-associated $\mathrm{CD} 44 \mathrm{v6}$ single-chain variable fragment; SiRNA, small interfering RNA. 


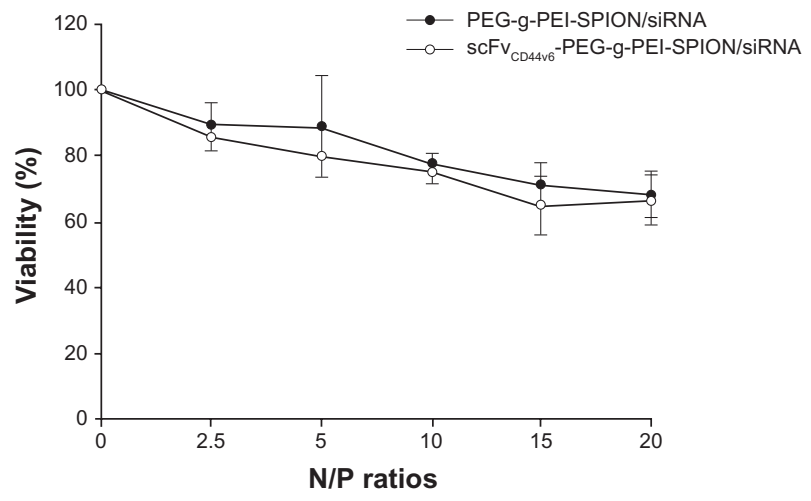

Figure 2 Viability of SGC-790I cells exposed to PEG-g-PEI-SPION/siRNA and $s c F v_{\mathrm{CD}_{4446}}$-PEG-g-PEI-SPION/siRNA polyplexes for 48 hours at various N/P ratios ranging from 2.5 to 20 . Cell viability of targeting and nontargeting polyplexes decreased gradually with increasing N/P ratio. At a higher N/P ratio of 20 , cell viability for both groups was still acceptable (over $66 \%$ ). There was no statistically significant difference between the two groups at individual N/P ratios $(P>0.05)$. Cell viability is expressed as the mean \pm standard deviation of the percentage of absorbance of controls, where $100 \%$ equals viability of the control cells. The experiments were carried out in triplicate.

Abbreviations: PEG, polyethylene glycol; PEI, polyethyleneimine; SPION, superparamagnetic iron oxide nanoparticles; $\mathrm{scFv}_{\mathrm{CD} 44 v 6}$, cancer-associated $\mathrm{CD} 44 \mathrm{v} 6$ singlechain variable fragment; SiRNA, small interfering RNA.

(Figure 3B). In the PEG-g-PEI-SPION group, mean fluorescence intensity was $63.60 \pm 2.91,66.40 \pm 3.69,60.00 \pm 2.30$, and $46.91 \pm 3.83$ at N/P ratios of 5, 10,15, and 20, respectively, while in the $\mathrm{scFv}_{\mathrm{CD} 44 \mathrm{v} 6}$-PEG-g-PEI-SPION group, mean fluorescence intensity was $72.67 \pm 4.95,77.35 \pm 4.59$, $78.74 \pm 3.53$, and $73.57 \pm 4.46$ at N/P ratios of $5,10,15$, and 20 , respectively. These results show that the mean fluorescence intensity of the $\mathrm{scFv}_{\mathrm{CD} 44 \mathrm{v} 6}$-PEG-g-PEI-SPION group was higher than that in the PEG-g-PEI-SPION group at the individual N/P ratios. At N/P ratios of 15 and 20, the difference was statistically significant $(P<0.05)$, demonstrating that $\mathrm{scFv}_{\mathrm{CD} 44 \mathrm{v} 6}$-PEG-g-PEI-SPION delivered more siRNA into cells than did the PEG-g-PEI-SPION.

\section{Cellular uptake and distribution of polyplexes}

Fluorescence images of SGC-7901 cells transfected with siNC-Cy3, complexed with $\mathrm{scFv}_{\mathrm{CD} 44 \mathrm{v} 6}$-PEG-g-PEI-SPION, and also with PEG-g-PEI-SPION at N/P ratio 15 are shown in Figure 4. Red fluorescence is seen in both the targeting and nontargeting groups, which clearly reveals the intracellular distribution of siRNA and delivery agents. In addition, the red fluorescence intensity in the targeting group was stronger than in the nontargeting group, which indicates that more polyplexes were internalized into the cells, which was consistent with the mean fluorescence intensity assessed by flow cytometry. After immunofluorescent staining, red fluorescence of siNCCy3 quenched markedly and appeared starlike in cells. Green fluorescence from fluorescein isothiocyanate-conjugated mouse monoclonal antibody only appeared in the transfection using $\mathrm{scFv}_{\mathrm{CD} 44 \mathrm{v}}-\mathrm{PEG}$-g-PEI-SPION but not in the one using PEG-g-PEI-SPION. It demonstrates that $\mathrm{scFv}_{\mathrm{CD} 44 \mathrm{v} 6}$ had been attached to PEG-g-PEI-SPION successfully and $\mathrm{scFv}_{\mathrm{CD} 44 \mathrm{v} 6}{ }^{-}$ PEG-g-PEI-SPION had been internalized into cells. In addition, when the fluorescence images were overlapped, the association

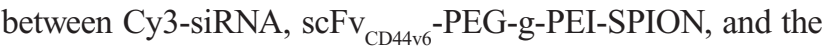
cell is shown. As demonstrated in the merged fluorescence image (Figure 4), some of the red and green fluorescence was scattered separately over the cell (indicated by red arrows), but
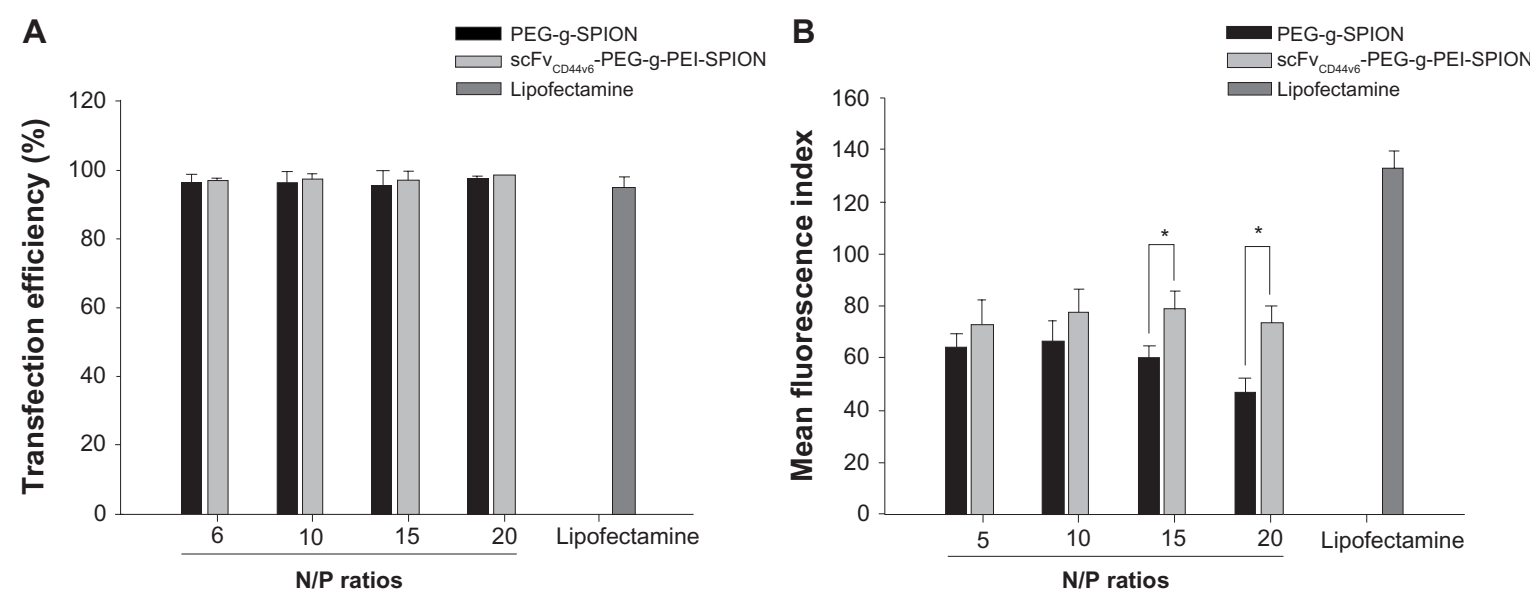

Figure 3 Transfection efficiency and mean fluorescence intensity analyses. Transfection efficiency of Lipofectamine ${ }^{\mathrm{TM}}$ (as a control), PEG-g-PEI-SPION, and scFv ${ }_{\text {CD44v6 }}$-PEGg-PEI-SPION at N/P ratios of 5, 10, 15, and 20 were all over 95\% (A), while no statistically significant difference between the three siRNA delivery agents was shown for transfection efficiency, but the difference was significant for mean fluorescence intensity (B). Mean fluorescence intensity was highest in the Lipofectamine group, and the mean fluorescence intensity of the $\mathrm{scFv}_{\mathrm{CD} 44 v 6}$-PEG-g-PEI-SPION group was higher than in the PEG-g-PEI-SPION group. Especially at N/P ratios of I5 and 20 , the difference between the targeting and nontargeting groups was significant $(P<0.05)$, indicating that the targeting vector transferred more siRNA into cells.

Abbreviations: PEG, polyethylene glycol; PEI, polyethyleneimine; SPION, superparamagnetic iron oxide nanoparticles; scFv $\mathrm{CD}_{\mathrm{C} 4 \mathrm{v}}$, cancer-associated $\mathrm{CD} 44 \mathrm{v} 6 \mathrm{single} \mathrm{chain}$ variable fragment. 


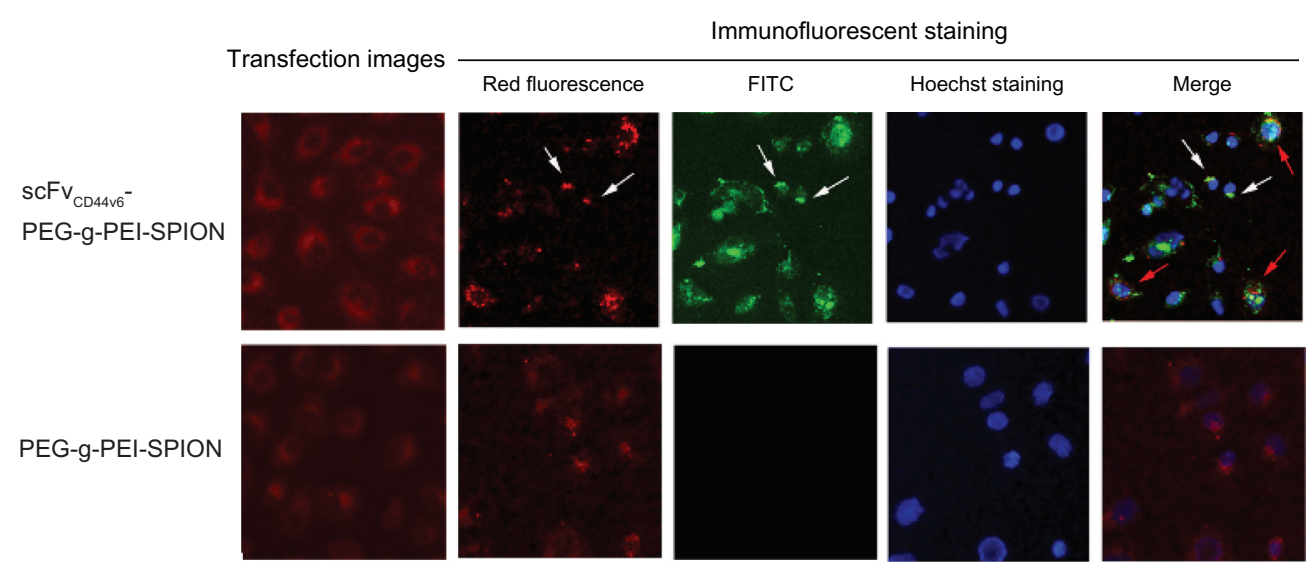

Figure 4 Fluorescence imaging and immunofluorescent staining experiments following siNC-Cy3 transfection. Fluorescence images of SGC-790I cells transfected with siNCCy3 by scFv $\mathrm{CD}_{\mathrm{C} 4 \mathrm{v} 6}-\mathrm{PEG}-\mathrm{g}-\mathrm{PEI}-\mathrm{SPION}$ and PEG-g-PEI-SPION at an N/P ratio of 15 were investigated under a fluorescence microscope. As shown in the transfection images, red fluorescence was shown in both groups, but was stronger in the $\mathrm{scFv}_{\mathrm{CD} 44 v 6}-\mathrm{PEG}$-g-PEI-SPION. After immunofluorescent staining, the red fluorescence of siNC-Cy3 was markedly quenched. Green fluorescence from the fluorescein isothiocyanate-conjugated mouse monoclonal antibody only appeared in the scFv ${ }_{\mathrm{CD} 44 \mathrm{v} 6}-\mathrm{PEG}-\mathrm{g}-\mathrm{PEI}-\mathrm{SPION}$ group, indicating that $\mathrm{scFv}_{\mathrm{CD} 44 v 6}$ had successfully attached to PEG-g-PEI-SPION. The merged picture demonstrates that some of the scFv $\mathrm{CD}_{44 v 6}-\mathrm{PEG}-\mathrm{g}$-PEI-SPION/siRNA complexes dissociated (red arrows) and some still assembled (white arrows) inside cells.

Abbreviations: PEG, polyethylene glycol; PEI, polyethyleneimine; SPION, superparamagnetic iron oxide nanoparticles; scFv ${ }_{\mathrm{CD} 44 \mathrm{v} v}$, cancer-associated $\mathrm{CD}_{44 \mathrm{v} 6}$ single-chain variable fragment; SiRNA, small interfering RNA.

some still gathered in the same sites (indicated by white arrows), implying that $\mathrm{scFv}_{\mathrm{CD} 44 \mathrm{v} 6}$-PEG-g-PEI-SPION/siRNA started to dissociate inside cells after incubation for 4 hours.

\section{Cancer targeting ability in vivo}

Superparamagnetic iron oxide contrast agents can enhance the image contrast of tissues through substantial shortening of $\mathrm{T}_{2}$ relaxation times in MRI, leading to hypointense signals at locations where the probes accumulate. To validate the tumor targeting ability of $\mathrm{scFv}_{\mathrm{CD} 44 \mathrm{v} 6}-\mathrm{PEG}-\mathrm{g}$-PEI-SPION in comparison with PEG-g-PEI-SPION, 12 mice bearing two tumors (SGC-7901 right thigh, A375 left thigh) were randomly divided into two groups, with six mice in each group. Because CD44v6 was highly expressed on SGC-7901 cells, while there was hardly any expression of CD44v6 on A375 cells (human malignant melanoma cells), ${ }^{20}$ SGC-7901 was selected as the target site, and A375 was the nontarget site. Iron concentrations of $1.12,2.24$, and $4.48 \mu \mathrm{g} / \mathrm{g}$ body weight were tested by MRI in preliminary studies, and the iron concentration of $4.48 \mu \mathrm{g} / \mathrm{g}$ body weight had the most obvious effect, and thus was chosen as the injection dose for tumor MRI. Before injection of the superparamagnetic iron oxide contrast agents, both tumors, indicated by red and blue arrows (Figure 5), were seen as hyperintense areas in the $\mathrm{T}_{2}$-weighted MRI images. After injection of PEG-g-PEI-SPION or $\mathrm{scFv}_{\mathrm{CD} 44 \mathrm{v} 6}-\mathrm{PEG}$-gPEI-SPION contrast agents, MRI scan was performed right after injection, and three and 12 hours following injection. At five minutes following injection of PEG-g-PEI-SPION or $\mathrm{scFv}_{\mathrm{CD} 44 \mathrm{v} 6}$-PEG-g-PEI-SPION, $\mathrm{T}_{2}$ signals in the liver dropped immediately, indicating that the SPION contrast agents had entered the systemic circulation. At three hours following injection of $\mathrm{scFv}_{\mathrm{CD} 44 \mathrm{v} 6}-\mathrm{PEG}$-g-PEI-SPION, patchy regions of darkening on the $\mathrm{T}_{2}$-weighted MRI images indicated by green arrow (Figure 5) were observed in the SGC-7901 tumor area, while the $\mathrm{T}_{2}$ signal did not drop in the $\mathrm{A} 375$ tumor area. The intensity of the $\mathrm{T}_{2}$ signal at the SGC-7901 tumor site recovered to the original level at 12 hours after injection. However, the $\mathrm{T}_{2}$ signals of the SGC-7901 and A375 tumor sites in the PEG-g-PEI-SPION group did not alter at different time points after injection.

To demonstrate further the existence of $\mathrm{scFv}_{\mathrm{CD} 44 \mathrm{v} 6}-\mathrm{PEG}-$ g-PEI-SPION in the SGC-7901 tumor area, but not at the A375 tumor site, Prussian blue staining was carried out. As shown in Figure 6, blue dots only appeared in the SGC-7901 tumor area after injection of $\mathrm{scFv}_{\mathrm{CD} 44 \mathrm{v} 6}$-PEG-g-PEI-SPION, whereas no blue particles were shown at the $\mathrm{A} 375$ tumor site of the same mouse. Moreover, no area of SGC-7901 tumor or A375 tumor was stained blue after injection of PEG-gPEI-SPION. All these results are in good agreement with the above in vivo MRI images.

\section{Discussion}

RNA interference is an effective therapeutic technology featuring high specificity and potent gene silencing. Synthetic siRNA has been used for specific inhibition of gene expression, analysis of gene function, and potential therapeutics. ${ }^{24-27}$ However, the main obstacle to developing siRNA as a small-molecule drug is poor intracellular uptake and nonspecific silencing. 


\section{L: A375 R: SGC-7901}

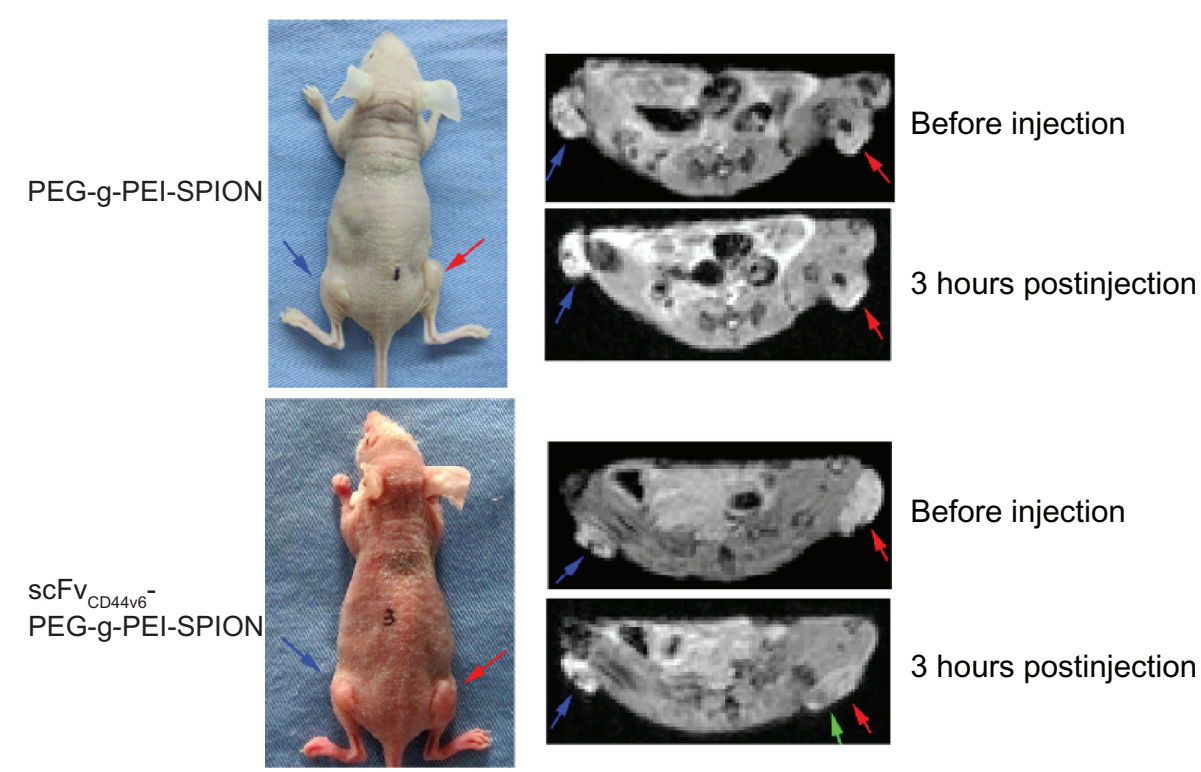

Figure 5 In vivo tumor targeting evaluation. Mice bearing two tumors (SGC-790 I right thigh, A375 left thigh) were used for MRI. Before injection of the SPIO contrast agents, both tumors indicated by red and blue arrows were seen as hyperintense areas in the $T_{2}$-weighted magnetic resonance images. At 3 hours after injection of scFv ${ }_{\text {intur }}-\mathrm{PEG}$ g-PEI-SPION, patchy regions of darkening on the $\mathrm{T}_{2}$-weighted MRI images indicated by green arrows were observed in the SGC-790I tumor site but not at the A375 tumor site. However, in the PEG-g-PEI-SPION group, $\mathrm{T}_{2}$ signals from the SGC-790I and A375 tumor sites did not alter before or after injection.

Abbreviations: PEG, polyethylene glycol; PEI, polyethyleneimine; SPION, superparamagnetic iron oxide nanoparticles; scFv $\mathrm{CD}_{\mathrm{C} 4 \mathrm{v} 6}$, cancer-associated $\mathrm{CD} 44 \mathrm{v} 6 \mathrm{single}$-chain variable fragment; SiRNA, small interfering RNA.

As a result, the main objective in siRNA therapy is the development of safe and highly efficient delivery systems that can encapsulate and transfer siRNA into specific cell types, such as cancerous cells. Targeting siRNA therapy will not achieve its goals until the issue of potent gene delivery vehicles with a clear targeting option has been resolved. Whereas viral vectors have proven to be extremely efficient in gene transfer, with concerns about the safety and immunogenicity, investigation of nonviral vectors with targeting capacities for selective gene/siRNA delivery has been prompted. ${ }^{28,29}$ Nanoparticles utilizing the cationic polymer, polyethylenimine, have advantages over other nonviral vectors. These nanoparticles are able to condense genetic material and possess a large surface area, which is able to be modified chemically and to adsorb targeting ligands, such as antibodies. All these features make polyethylenimine-based nanoparticles one of the most promising nonviral vectors. Further, PEG-g-PEI is synthesized by introducing PEG to polyethylenimine to reduce cytotoxicity and suppress nonspecific interactions of polyethylenimine with blood components. ${ }^{30,31}$ Moreover, PEG-g-PEI could complex
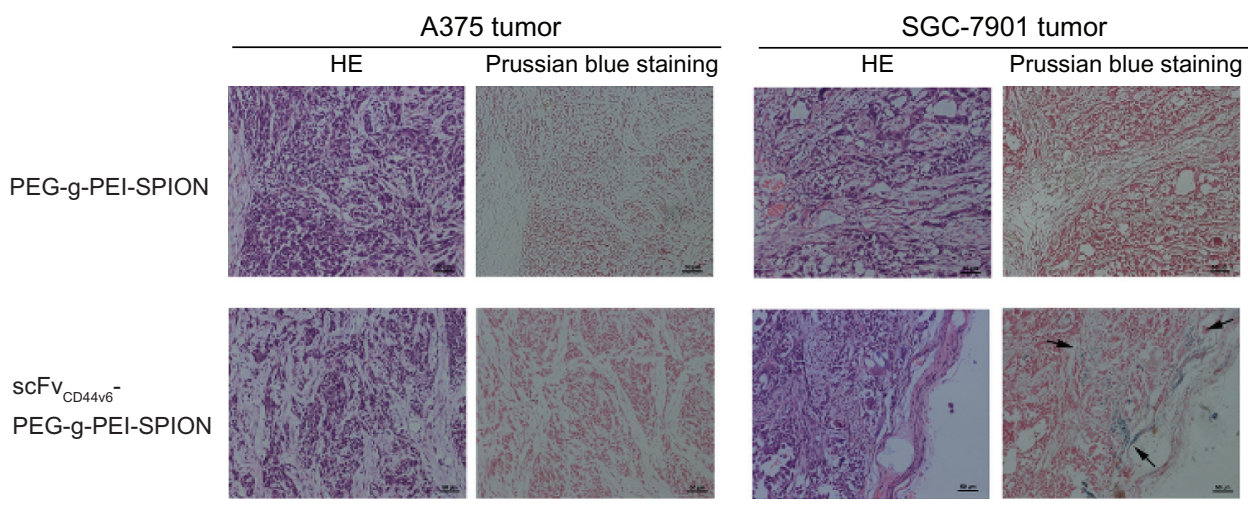

Figure 6 Histology analyses. Hematoxylin and eosin staining and Prussian blue staining were performed on tumor tissues. After Prussian blue staining, blue-positive particles indicated by arrows only appeared in the SGC-790I tumor area after injection of scFv ${ }_{\mathrm{CD} 44 v 6}-\mathrm{PEG}-\mathrm{g}$-PEI-SPION, whereas no blue particles were shown at the A375 tumor site in the same mouse. Moreover, in the PEG-g-PEI-SPION group, no SGC-790I tumor or A375 tumor sites were stained blue following injection.

Abbreviations: PEG, polyethylene glycol; PEI, polyethyleneimine; SPION, superparamagnetic iron oxide nanoparticles; scFv ${ }_{\mathrm{CD} 44 v 6}$, cancer-associated $\mathrm{CD} 44 \mathrm{v} 6$ single-chain variable fragment; SiRNA, small interfering RNA. 
SPION easily and various targeting ligands such as antibodies can be introduced through PEG linkage. With these approaches, antibody-directed cell type-specific delivery of genes was achieved, and targeting events were detectable with the noninvasive MRI technique. ${ }^{13,14,32}$

In this study, PEG-g-PEI-SPION and $\mathrm{scFv}_{\mathrm{CD} 44 \mathrm{v} 6}$ were chosen as two essential components to construct a targeted siRNA delivery vector with MRI imaging functions. $\mathrm{ScFv}_{\mathrm{CD}_{44 \mathrm{v} 6}}$ was generated by phage display technology as described in our previous study, and its cancer-targeting ability in vitro has been demonstrated by immunofluorescent staining, Western blotting, and flow cytometric analyses. An $\mathrm{scFv}_{\mathrm{CD} 44 \mathrm{v} 6}-\mathrm{PEG}-$ g-PEI-SPION targeting nanocarrier was synthesized through PEG linkage. A gel retardation assay showed that both PEG-gPEI-SPION/siRNA and $\mathrm{scFv}_{\mathrm{CD} 44 \mathrm{v} 6}$-PEG-g-PEI-SPION/siRNA at the same N/P ratio above 10 were completely complexed. These results demonstrate that a desirable combination of delivery agents and siRNA occurred at an N/P ratio above 10. A higher N/P ratio may not only lead to better siRNA condensation, but may also result in greater cytotoxicity due to electrostatic interaction between the nanoparticles and negatively charged cell membranes. An MTT assay was used to determine the cytotoxicity of the polyplexes. With the N/P ratio increasing from 2.5 to 20 , the viability of the targeting and nontargeting polyplexes decreased gradually. Cells retained more than $75 \%$ viability as the N/P ratio reached 10 . Even at a higher $\mathrm{N} / \mathrm{P}$ ratio of 20 , the cell viability was still over $66 \%$ in both groups. Cytotoxicity was still acceptable even at an N/P ratio of 20. No statistically significant difference was shown between the two groups at the individual N/P ratios, demonstrating that $\mathrm{scFv}_{\mathrm{CD} 44 \mathrm{v} 6}$ had no obvious cytotoxicity.

The transfection efficiency of siRNA to SGC-7901 with high CD44v6 expression by PEG-g-PEI-SPION and $\mathrm{ScFv}_{\mathrm{CD} 44 \mathrm{v} 6}-\mathrm{PEG}-\mathrm{g}-\mathrm{PEI}-\mathrm{SPION}$ at N/P ratios of 5, 10, 15, and 20 was consistently over $95 \%$, reaching the level of Lipofectamine. Although no increase of transfection efficiency was seen in the targeting group, targeted siRNA delivery of $\mathrm{scFv}_{\mathrm{CD} 44 \mathrm{v} 6}$-PEG-g-PEI-SPION was indirectly shown by mean fluorescence intensity, which was an indirect measure of intracellular siRNA. Whereas mean fluorescence intensity was highest in the Lipofectamine group, the mean fluorescence intensity of the targeting group was higher than in the nontargeting one, especially at N/P ratios of 15 and 20, indicating that the targeting vector transferred more siRNA into the cells. According to the N/P ratio formula, one individual nanoparticle carried less siRNA at a higher N/P ratio. At the same cellular amount of nanoparticle uptake, the total number of cells with internalized siRNA was less at a higher N/P ratio. Correspondingly, we found that mean fluorescence intensity dropped gradually from 63.60 to 46.91 at N/P ratios ranging from 5 to 20 in the nontargeting group. However, cellular uptake of nanoparticles involves three major stages, including endocytosis, sequestration in early endosomes, and translocation to later endosomes or lysosomes. The endocytosis was probably assisted by receptors specific to ligands. ${ }^{33} \mathrm{scFv}_{\mathrm{CD} 44 \mathrm{v} 6}$-PEG-g-PEI-SPION, which possesses a ligand specific to the cellular CD44v6 receptor, mediated endocytosis and enhanced the intake of $\mathrm{scFv}_{\mathrm{CD}_{44 \mathrm{v}}{ }^{-}}$ PEG-g-PEI-SPION/siRNA complexes. The mean fluorescence intensity of the targeting group was relatively stable and higher than that of the nontargeting group at all N/P ratios. As the mean fluorescence intensity in the nontargeting group decreased more at higher N/P ratios, the difference between the two groups became statistically significant. These results demonstrate the antibody-directed cell type-specific delivery of siRNA by $\mathrm{scFv}_{\mathrm{CD} 44 \mathrm{v} 6}$-PEG-g-PEI-SPION, and this was also confirmed by the results of fluorescence imaging and immunofluorescent staining experiments.

Encouragingly, the in vivo tumor targeting ability of $\mathrm{ScFv}_{\mathrm{CD} 44 \mathrm{v} 6}$-PEG-g-PEI-SPION was validated by MRI technology. After $\mathrm{scFv}_{\mathrm{CD} 44 \mathrm{v} 6}$-PEG-g-PEI-SPION and PEG-g-PEISPION were injected through the tail veins of mice bearing SGC-7901 tumor (right thigh) and A375 tumor (left thigh), MRI scans revealed that $\mathrm{scFv}_{\mathrm{CD} 44 \mathrm{v} 6}-\mathrm{PEG}-\mathrm{g}$-PEI-SPION could accumulate specifically at the SGC-7901 tumor site and lead to patches of hypointense signals. However, PEG-g-PEISPION failed to accumulate at SGC-7901 or A375 tumor sites. The same results were shown in the histology analysis. These results highlight the specific cancer-targeting ability of $\mathrm{scFv}_{\mathrm{CD} 44 \mathrm{v} 6}$-PEG-g-PEI-SPION in vivo.

In summary, an antibody-directed nanoparticulate vector with siRNA delivery and MRI functions was generated by attaching $\mathrm{scFv}_{\mathrm{CD} 44 \mathrm{v} 6}$ to PEG-g-PEI-SPION. This new nonviral carrier effectively and specifically transferred siRNA in vitro. The tumor-targeting effect in vivo was visible by MRI technology. The next step in our research is to analyze further the gene silencing effect in vitro and in vivo and monitor the therapeutic outcome. $\mathrm{ScFv}_{\mathrm{CD} 44 \mathrm{v} 6}$-PEG-g-PEI-SPION can also transfer other genetic material, such as reporter and therapeutic genes, and can be used for the MRI diagnosis of epithelial cancers. Future efforts should be focused on these issues.

\section{Acknowledgments}

This work was supported by the National Natural Science Foundation of China (Grant No. 81072045, 30670951 and 50830107), the Natural Science Foundation of Guangdong 
Province (Grant No. 6021322 and 9351027501000003 ), and the Industry-University-Research Foundation of Guangdong Province, China (Grant No. 2009B090300277).

\section{Disclosure}

The authors report no conflicts of interest in this work.

\section{References}

1. Mitelman F. Catalogue of chromosome aberrations in cancer. Cytogenet Cell Genet. 1983;36(1-2):1-515.

2. Desai AM, Pareek M, Nightingale PG, Fielding JW. Improving outcomes in gastric cancer over 20 years. Gastric Cancer. 2004;7(4):196-201.

3. Boyle P. Global burden of cancer. Lancet. 1997;349 Suppl 2: SII23-SII26.

4. Neugut AI, Hayek M, Howe G. Epidemiology of gastric cancer. Semin Oncol. 1996;23(3):281-291.

5. El-Aneed A. An overview of current delivery systems in cancer gene therapy. J Control Release. 2004;94(1):1-14.

6. Cusack JC Jr, Tanabe KK. Introduction to cancer gene therapy. Surg Oncol Clin N Am. 2002;11(3):497-519.

7. Fischer D, Bieber T, Li Y, Elsässer HP, Kissel T. A novel nonviral vector for DNA delivery based on low molecular weight, branched polyethylenimine: effect of molecular weight on transfection efficiency and cytotoxicity. Pharm Res. 1999;16(8):1273-1279.

8. Ogris M, Brunner S, Schüller S, Kircheis R, Wagner E. PEGylated DNA/transferrin-PEI complexes: reduced interaction with blood components, extended circulation in blood and potential for systemic gene delivery. Gene Ther. 1999;6(4):595-605.

9. Fischer D, von Harpe A, Kunath K, Petersen H, Li Y, Kissel T. Copolymers of ethylene imine and $\mathrm{N}$-(2-hydroxyethyl)-ethylene imine as tools to study effects of polymer structure on physicochemical and biological properties of DNA complexes. Bioconjug Chem. 2002;13(5): 1124-1133.

10. Fischer D, Osburg B, Petersen H, Kissel T, Bickel U. Effect of poly(ethylene imine) molecular weight and pegylation on organ distribution and pharmacokinetics of polyplexes with oligodeoxynucleotides in mice. Drug Metab Dispos. 2004;32(9):983-992.

11. Merkel OM, Librizzi D, Pfestroff A, et al. Stability of siRNA polyplexes from poly(ethylenimine) and poly(ethylenimine)-g-poly(ethylene glycol) under in vivo conditions: effects on pharmacokinetics and biodistribution measured by fluorescence fluctuation spectroscopy and single photon emission computed tomography (SPECT) imaging. J Control Release. 2009;138(2):148-159.

12. Wu Y, Wang W, Chen Y, et al. The investigation of polymer-siRNA nanoparticle for gene therapy of gastric cancer in vitro. Int J Nanomedicine. 2010;5:129-136.

13. Nasongkla N, Bey E, Ren J, et al. Multifunctional polymeric micelles as cancer-targeted, MRI-ultrasensitive drug delivery systems. Nano Lett. 2006;6(11):2427-2430.

14. Khemtong C, Kessinger CW, Ren J, et al. In vivo off-resonance saturation magnetic resonance imaging of alphavbeta3-targeted superparamagnetic nanoparticles. Cancer Res. 2009;69(4):1651-1658.
15. Chen $\mathrm{G}, \mathrm{Chen} \mathrm{W}, \mathrm{Wu} \mathrm{Z}$, et al. MRI-visible polymeric vector bearing CD3 single chain antibody for gene delivery to T cells for immunosuppression. Biomaterials. 2009;30(10):1962-1970.

16. Goodison S, Urquidi V, Tarin D. CD44 cell adhesion molecules. Mol Pathol. 1999;52(4):189-196.

17. Rudzki Z, Jothy S. CD44 and the adhesion of neoplastic cells. Mol Pathol. 1997;50(2):57-71.

18. Endo K, Terada T. Protein expression of CD44 (standard and variant isoforms) in hepatocellular carcinoma: relationships with tumor grade, clinicopathologic parameters, p53 expression, and patient survival. J Hepatol. 2000;32(1):78-84.

19. Ponta H, Sherman L, Herrlich PA. CD44: from adhesion molecules to signaling regulators. Nat Rev Mol Cell Biol. 2003;4(1):33-45.

20. Chen Y, Huang K, Li X, Lin X, Zhu Z, Wu Y. Generation of a stable anti-human $\mathrm{CD} 44 \mathrm{v} 6 \mathrm{scFv}$ and analysis of its cancer-targeting ability in vitro. Cancer Immunol Immunother. 2010;59(6):933-942.

21. Sun S, Zeng H, Robinson DB, et al. Monodispersed $\mathrm{MFe}_{2} \mathrm{O}_{4}(\mathrm{M}=\mathrm{Fe}$, Co, Mn) nanoparticles. J Am Chem Soc. 2004;126(1):273-279.

22. Hong G, Yuan R, Liang B, Shen J, Yang X, Shuai X. Folate-functionalized polymeric micelle as hepatic carcinoma-targeted, MRI-ultrasensitive delivery system of antitumor drugs. Biomed Microdevices. 2008; 10(5):693-700.

23. Breunig M, Hozsa C, Lungwitz U, et al. Mechanistic investigation of poly(ethylene imine)-based siRNA delivery: disulfide bonds boost intracellular release of the cargo. J Control Release. 2008;130(1): 57-63.

24. Fuchs F, Boutros M. Cellular phenotyping by RNAi. Brief Funct Genomic Proteomic. 2006;5(1):52-56.

25. Cullen LM, Arndt GM. Genome-wide screening for gene function using RNAi in mammalian cells. Immunol Cell Biol. 2005;83(3):217-223.

26. Takeshita F, Ochiya T. Therapeutic potential of RNA interference against cancer. Cancer Sci. 2006;97(8):689-696.

27. Bitko V, Musiyenko A, Shulyayeva O, Barik S. Inhibition of respiratory viruses by nasally administered siRNA. Nat Med. 2005;11(1):50-55.

28. Li X, Stuckert P, Bosch I, Marks JD, Marasco WA. Single-chain antibody-mediated gene delivery into ErbB2-positive human breast cancer cells. Cancer Gene Ther. 2001;8(8):555-565.

29. Song E, Zhu P, Lee SK, et al. Antibody mediated in vivo delivery of small interfering RNAs via cell-surface receptors. Nat Biotechnol. 2005; 23(6):709-717.

30. Lungwitz U, Breunig M, Blunk T, Göpferich A. Polyethyleniminebased non-viral gene delivery systems. Eur J Pharm Biopharm. 2005; 60(2):247-266.

31. Ogris M, Walker G, Blessing T, Kircheis R, Wolschek M, Wagner E. Tumor-targeted gene therapy: strategies for the preparation of ligandpolyethylene glycol-polyethylenimine/DNA complexes. J Control Release. 2003;91(1-2):173-181.

32. Leakakos T, Ji C, Lawson G, Peterson C, Goodwin S. Intravesical administration of doxorubicin to swine bladder using magnetically targeted carriers. Cancer Chemother Pharmacol. 2003;51(6): $445-450$.

33. Xiao Y, Forry SP, Gao X, Holbrook RD, Telford WG, Tona A. Dynamics and mechanisms of quantum dot nanoparticle cellular uptake. J Nanobiotechnology. 2010;8:13.
International Journal of Nanomedicine

\section{Publish your work in this journal}

The International Journal of Nanomedicine is an international, peerreviewed journal focusing on the application of nanotechnology in diagnostics, therapeutics, and drug delivery systems throughout the biomedical field. This journal is indexed on PubMed Central, MedLine, CAS, SciSearch $\AA$, Current Contents ${ }^{\circledR} /$ Clinical Medicine,

\section{Dovepress}

Journal Citation Reports/Science Edition, EMBase, Scopus and the Elsevier Bibliographic databases. The manuscript management system is completely online and includes a very quick and fair peer-review system, which is all easy to use. Visit http://www.dovepress.com/ testimonials.php to read real quotes from published authors. 